Future trends of plastic bottle recycling: Compatibilization of PET and PLA Gere D., Czigány T.

This accepted author manuscript is copyrighted and published by Elsevier. It is posted here by agreement between Elsevier and MTA. The definitive version of the text was subsequently published in [Polymer Testing, 81, 2020, DOI:

10.1016/j.polymertesting.2019.106160]. Available under license CC-BY-NC-ND. 


\title{
Future trends of plastic bottle recycling: Compatibilization of PET and PLA
}

\author{
D. Gere ${ }^{a}$, T. Czigany $y^{a, b, *}$ \\ ${ }^{a}$ Department of Polymer Engineering, Faculty of Mechanical Engineering, Budapest \\ University of Technology and Economics, H-1111 Budapest, Muegyetem rkp. 3, Hungary \\ ${ }^{b}$ MTA-BME Research Group for Composite Science and Technology, H-1111 Budapest, \\ Muegyetem rkp. 3., Hungary \\ * corresponding author: czigany@eik.bme.hu
}

(1) (1) (1)

Abstract. We improved the recyclability of mixed poly(ethylene-terephthalate) (PET) and poly(lactic acid) (PLA) bottle waste. We made uncompatibilized and compatibilized PET/PLA blends of different weight ratios with a twin-screw extruder. Then, we analyzed the mechanical properties, the miscibility and the thermal stability of the blends with and without compatibilizers. From the change in intrinsic viscosities (IV), we concluded that different reactions occur between the polymer chains due to the compatibilizers. We observed that when ethylene-butyl acrylate-glycidyl methacrylate (E-BA-GMA) as compatibilizer was added, the blends became tougher; elongation at break and Charpy impact strength increased, but Young's modulus of the blends decreased. In addition, the compatibilizers improved the thermal stability of the blends and this may have been caused by a number of mechanisms.

Keywords: recycling; poly(ethylene-terephthalate); poly(lactic acid); blends; compatibilization

\section{Introduction}

Nowadays environmentally conscious manufacturers not only manufacture their products from partly or fully recycled materials, but are increasingly using biopolymers besides or instead of petroleum-based polymers as well. Similarly to petroleum-based plastics, most biopolymers are used by the packaging industry $[1,2]$. However, due to their function, they have a very short lifetime (a few weeks on average), therefore they become waste in a short time [3]. In 2016, 16.7 million tonnes of plastic packaging waste was collected, of which $40.8 \%$ was recycled, $38.8 \%$ was used for energy generation (incineration) and $20.4 \%$ was landfilled [1].

3 In May 2019, the Council of the European Union proposed new EU-wide regulations 34 concerning 10 single-use plastic products, which are most often found in the seas and on the 
1 beaches of Europe. The Member States, no later than 2 years after the Directive enters into

2 force, have to ban the following single-use plastic products: plastic cotton buds, cutlery, plates, straws, stirrers, and sticks for balloons; all products made of oxo-plastic; and cups, food and beverage containers made of expanded polystyrene. In addition, 90\% of single-use plastic bottles have to be collected separately by 2029 [4].

In 2017 , only around $2 \%$ of the total production of plastic was biopolymer, but its volume is increasing year by year $[2,5,6]$. As the Directive enters into force, this increase will probably be even greater. Poly(lactic acid) (PLA) is one of the most popular biodegradable biopolymers used in the packaging industry to produce films, sheets, bottles and foams [2, 7-11]. The recycling of petroleum-based polymers is already well established and it is also possible to biologically recycle biodegradable polymers (e.g. industrial composting) [12]. However, in our opinion, the public and the selective waste collection system are not yet prepared for the separate collection of biopolymers, therefore they may be mixed in the plastic waste stream. This assumption is confirmed by the fact that some publications [13-16] have already investigated the influence of bioplastic (PLA) "contamination" on the recycling process of petroleum-based plastic waste.

The separation of mixed poly(ethylene-terephthalate) (PET) and PLA bottles in the postconsumer plastic waste stream is difficult and expensive with conventional methods. Manual sorting by visual appearance cannot be done because in most cases both PET and PLA bottles are transparent, therefore they look very similar. Their density is also very similar (1.2-1.3 $\mathrm{g} / \mathrm{cm}^{3}$ for PLA and $1.3-1.4 \mathrm{~g} / \mathrm{cm}^{3}$ for PET) and higher than that of water, therefore the widespread traditional water-based float-sink separation process is not effective [17, 18]. Moreover, according to reports [17], the effectivity of Fourier Transform Near-Infrared (FTNIR) spectroscopy for separating PLA bottles from PET bottles is only $86 \%-99 \%$. Researchers [13, 16, 19] demonstrated that even small amounts of PLA have a significant negative effect on the properties of PET. At the processing temperature of PET, PLA already degrades, which leads to the yellowing of the product. Moreover, PET and PLA are thermodynamically immiscible, therefore holes, peaks or clusters can appear in the products. In addition, the glass transition temperature of the two polymers is also different, resulting in opaqueness or haziness in PLA-contaminated PET products [17]. These are important problems because in mass production, optical and surface properties may be even more important than mechanical properties [20].

33 There are many methods for compatibilizing thermodynamically immiscible polymer blends: non-reactive (ex situ) and reactive (in situ) compatibilizers, nanoparticles, peroxides, irradiation 
treatment or a combination of these [21, 22]. In the case of non-reactive compatibilization, premade copolymers are used to improve the miscibility of the components of the blend. Nonreactive compatibilization is a two-step process. In the first step, a copolymer with suitable functionality is created, and in the second step, the copolymer is mixed with the immiscible blend in the melted state [22]. The main advantage of copolymers as compatibilizers is that one of the constituents or blocks is miscible with one of the components of the blend, while the other constituent or block is miscible with the other component of the blend [22-24]. The functionalized polymer can be a graft or block copolymer [22, 25-30]. In immiscible polymer blends, the components often contain reactive functional groups (e.g. hydroxyl, amine, or carboxylic acid groups), therefore polymers with reactive functional groups (e.g. epoxy, anhydride, oxazoline, carboxylic acid, and isocyanate groups) can be used as reactive compatibilizers. The reactive functional groups of the compatibilizer can react with the reactive functional groups of the components of the blend during melt blending, thereby forming in situ grafted and/or block copolymers. The formed graft and/or block copolymers can act as an effective compatibilizer in the blend [21,22]. The ethylene-butyl acrylate-glycidyl methacrylate (E-BA-GMA) terpolymer is recommended as an impact modifier for a variety of polymers by the producer, DuPont Co. [31]. According to the literature [32-35], the epoxy reactive functional group of the E-BA-GMA terpolymer can react effectively with the $-\mathrm{OH}$ end groups of polyesters in the melted state, thereby forming active graft copolymers at the interface. Therefore, it is used as a reactive compatibilizer in many publications $[32,36-40]$.

Degradation, which usually results in reduced molecular weight, is often a problem during the recycling of polymers. The viscosity of the material can drastically decrease due to the shortened molecular chains, which not only causes processing difficulties but also affects the properties of products made from secondary raw material $[41,42]$. The chain extenders, through their reactive functional groups, reconnect the degraded polymer chain segments, thereby increasing melt strength. For polyesters, many researchers [42-46] use the Joncryl ADR 4368 (BASF) multifunctional epoxy-based styrene-acrylic oligomer to compensate for degradation and/or increase molecular weight. However, nowadays it is also used as a reactive compatibilizer due to its reactive epoxy functional group [43, 47-50].

Publications and statistical data show that in the near future, biopolymers will increasingly appear in the plastic waste stream, therefore we must be prepared to collect them separately as soon as possible. Until then, mixed waste has to be recycled together and a solution must be 
1 is that our goal is not only to analyse the biopolymer "contamination" in the petroleum-based

2 polymer waste stream, but also to investigate the effect of petroleum-based polymer impurities

3 on the recycling process of biopolymers, as their proportions change over time. In addition, we

4 also seek a solution for the upgraded recycling of mixed PET and PLA bottles. In our research,

5 we specifically investigated the properties of the blends, as many articles have already analysed

6 the changes in properties of PET and PLA separately, during recycling.

7

\section{Experimental}

\subsection{Materials}

We used virgin bottle grade PET type NeoPET 80 (intrinsic viscosity (IV): $0.80 \mathrm{dl} / \mathrm{g}$, density: $1.34 \mathrm{~g} / \mathrm{cm}^{3}$ ) supplied by NeoGroup (Klaipèda, Lithuania), and virgin bottle grade PLA type Ingeo 7001D (MFI $\left(210^{\circ} \mathrm{C}, 2.16 \mathrm{~kg}\right): 6 \mathrm{~g} / 10 \mathrm{~min}$, density: $\left.1.24 \mathrm{~g} / \mathrm{cm}^{3}\right)$, supplied by

13 NatureWorks LLC. (Minnetonka, USA). As compatibilizer, we used ethylene-butyl acrylate14 glycidyl methacrylate terpolymer (E-BA-GMA) pellets type Elvaloy PTW (MFI $\left(190^{\circ} \mathrm{C}, 2.16\right.$ $\mathrm{kg}$ ): $12 \mathrm{~g} / 10 \mathrm{~min}$, density: $0.94 \mathrm{~g} / \mathrm{cm}^{3}$ ) supplied by DuPont Co. (Midland, USA). Its E/BA/GMA monomer ratio is $66.75 / 28 / 5.25(\mathrm{wt} \% / \mathrm{wt} \% / \mathrm{wt} \%)$. To compensate for molar mass reduction due to degradation, we used chain extender type CESA-extend NCA0025531-ZA supplied by Clariant AG (Muttenz Switzerland), which contains a multifunctional epoxy-based oligomeric reagent (Joncryl ADR 4368). Table 1 shows the composition of the different blends.

\begin{tabular}{|c|c|c|c|c|c|}
\hline \multicolumn{2}{|c|}{ PET/PLA/E-BA-GMA/CESA } & \multirow{2}{*}{$\begin{array}{c}\text { PET }^{\text {a) }}[\mathbf{w t} \%] \\
100\end{array}$} & \multirow{2}{*}{$\begin{array}{c}\mathbf{P L A}^{\text {a) }}[\mathbf{w t} \%] \\
0\end{array}$} & \multirow{2}{*}{$\begin{array}{c}\text { E-BA-GMA }{ }^{\text {b) }} \\
{[\mathrm{pph}]}\end{array}$} & \multirow{2}{*}{$\begin{array}{c}\text { CESA }^{\text {b) }} \\
{[p p h]}\end{array}$} \\
\hline 1. & $100 / 0 / 0 / 0$ & & & & \\
\hline 2. & $85 / 15 / 0 / 0$ & \multirow{4}{*}{85} & \multirow{4}{*}{15} & & \\
\hline 3. & $85 / 15 / 6 / 0$ & & & 6 & \\
\hline 4. & $85 / 15 / 12 / 0$ & & & 12 & \\
\hline 5. & $85 / 15 / 12 / 2$ & & & 12 & 2 \\
\hline 6. & $75 / 25 / 0 / 0$ & \multirow{4}{*}{75} & \multirow{4}{*}{25} & & \\
\hline 7. & $75 / 25 / 6 / 0$ & & & 6 & \\
\hline 8. & $75 / 25 / 12 / 0$ & & & 12 & \\
\hline 9. & $75 / 25 / 12 / 2$ & & & 12 & 2 \\
\hline 10. & $50 / 50 / 0 / 0$ & \multirow{4}{*}{50} & \multirow{4}{*}{50} & & \\
\hline 11. & $50 / 50 / 6 / 0$ & & & 6 & \\
\hline 12. & $50 / 50 / 12 / 0$ & & & 12 & \\
\hline 13. & $50 / 50 / 12 / 2$ & & & 12 & 2 \\
\hline
\end{tabular}




\begin{tabular}{|c|c|c|c|c|c|}
\hline 14. & $25 / 75 / 0 / 0$ & \multirow{4}{*}{25} & \multirow{4}{*}{75} & & \\
\hline 15. & $25 / 75 / 6 / 0$ & & & 6 & \\
\hline 16. & $25 / 75 / 12 / 0$ & & & 12 & \\
\hline 17. & $25 / 75 / 12 / 2$ & & & 12 & 2 \\
\hline 18. & $15 / 85 / 0 / 0$ & \multirow{4}{*}{15} & \multirow{4}{*}{85} & & \\
\hline 19. & $15 / 85 / 6 / 0$ & & & 6 & \\
\hline 20. & $15 / 85 / 12 / 0$ & & & 12 & \\
\hline 21. & $15 / 85 / 12 / 2$ & & & 12 & 2 \\
\hline 22. & $0 / 100 / 0 / 0$ & 0 & 100 & & \\
\hline
\end{tabular}

${ }^{\text {a) Referred to only PET+PLA. }}$

b) Part or grams per 100 parts or grams of PET+PLA.

Table 1. Compositions of the prepared PET/PLA blends

\subsection{Material preparation and processing}

Before melt blending, the dry-blended mixture of PET and PLA was dried at $140{ }^{\circ} \mathrm{C}$ in a Faithful WGLL-125 BE (Huanghua, China) hot air drying oven for 6 hours and CESA-extend chain extender was dried at $80{ }^{\circ} \mathrm{C}$ in a Faithful WGLL-45 BE (Huanghua, China) hot air drying oven for 4 hours.

The twenty-two different blends were compounded in a melted state with a Labtech Scientific LTE 26-44 (Samutprakarn, Thailand) co-rotating twin-screw extruder (screw diameter: $26 \mathrm{~mm}$, length/diameter (L/D) ratio: 44). All extruded blends were immediately cooled in a water bath at room temperature, and pelletized. The temperature profile of the extruder (from hopper to die) was $235^{\circ} \mathrm{C}-240{ }^{\circ} \mathrm{C}-245{ }^{\circ} \mathrm{C}-250{ }^{\circ} \mathrm{C}-255^{\circ} \mathrm{C}-260{ }^{\circ} \mathrm{C}-265^{\circ} \mathrm{C}-270{ }^{\circ} \mathrm{C}-275^{\circ} \mathrm{C}-270{ }^{\circ} \mathrm{C}-265$ ${ }^{\circ} \mathrm{C}$. The rotational speed of the extruder screws was $50 \mathrm{rpm}$ and melt pressure was 15-20 bar. Before injection molding, the compounds were dried at $140{ }^{\circ} \mathrm{C}$ in a Faithful WGLL-125 BE hot air drying oven for 6 hours. The injection molded dumbbell-shaped tensile specimens were manufactured with an Arburg Allrounder 370 S 700-290 injection molding machine (Loßburg, Germany). The injection rate was $50 \mathrm{~cm}^{3} / \mathrm{s}$, holding pressure was $700 \mathrm{bar}$, holding time was 20 $\mathrm{s}$, residual cooling time was $30 \mathrm{~s}$, and melt and mold temperatures were $280{ }^{\circ} \mathrm{C}$ and $30^{\circ} \mathrm{C}$, respectively.

\subsection{Methods}

24 Intrinsic viscosity (IV) was measured with a computer-controlled PSL Rheotek RPV-1 25 (Granger, USA) automatic solution viscometer equipped with an optical sensor. The solvent was phenol/1,1,2,2-tetrachloroethane mixture in the ratio of $60 \%: 40 \%$. Concentration was $0.5 \mathrm{~g} / \mathrm{dl}$, and the testing temperature was $30^{\circ} \mathrm{C}$. 
Tensile tests were done on a Zwick Z005 (Ulm, Germany) testing machine at $22^{\circ} \mathrm{C}$. An AST

2 Mess \& Regeltechnik KAP-TC (Dresden, Germany) type load cell was used (measuring range

$3 \quad 0-5000 \mathrm{~N}$, preload $1 \mathrm{~N}$ ). We calculated the tensile modulus between $0.05 \%$ and $0.25 \%$ strain

4 using a crosshead speed of $1 \mathrm{~mm} / \mathrm{min}$, and determined tensile strength (calculated at the $1^{\text {st }}$ local maximum force of the tensile curve), and elongation at the maximum force using a crosshead speed of $50 \mathrm{~mm} / \mathrm{min}$. The measurements were performed on ISO 527-2/1A dumbbell-shaped specimens with an overall length of $170 \mathrm{~mm}$ and a cross-section of $4 \mathrm{~mm} \times 10 \mathrm{~mm}$. We repeated the tests 5 times for each composition, and calculated the average value and standard deviation. Impact strength was determined with the Charpy impact test on a Ceast Resil Impactor Junior impact tester (Torino, Italy), with a $2 \mathrm{~J}$ pendulum. The measurements were performed on $2 \mathrm{~mm}$ notched ISO 179-1/1eA specimens with a length of $80 \mathrm{~mm}$ and a cross-section of $4 \mathrm{~mm} \times$ $10 \mathrm{~mm}$. The tests were carried out at $22{ }^{\circ} \mathrm{C}$ and at a relative humidity of $50 \%$. We repeated the tests 10 times for each composition, and calculated the average and standard deviation. The fracture surfaces of the specimens were studied with a Jeol JSM-6380LA (Tokyo, Japan) scanning electron microscope (SEM). Before the test, the samples were sputter-coated with a gold/palladium alloy.

Thermogravimetric analysis (TGA) measurements were performed with a TA Instruments Q500 automatic sampling device (New Castle, USA). The measurement temperature range was $50-600{ }^{\circ} \mathrm{C}$, the heating rate was $10^{\circ} \mathrm{C} / \mathrm{min}$, and the mass of the samples was between $5 \mathrm{mg}$ and $7 \mathrm{mg}$. The tests were carried out in nitrogen protective gas (40 ml/min) and with an industrial grade air $\left(78 \% \mathrm{~N}_{2}, 21 \% \mathrm{O}_{2}, 1 \%\right.$ other $)$ measuring atmosphere $(60 \mathrm{ml} / \mathrm{min})$.

\section{Results and discussion}

\subsection{Intrinsic viscosity (IV)}

Figure 1 shows the results of the intrinsic viscosity measurement. Without additives, IV increased with the increase of the weight fraction of PLA, which is explained by the fact that PLA has higher molecular weight than PET. The results indicated that the IV of all blends increased with the increase in the proportion of E-BA-GMA. In addition, when compatibilizer and chain extender were simultaneously applied, IV further increased. Based on the results, it can be concluded that if the ratio of PLA in the blend is equal to or greater than $50 \%$, the chain extender used besides the compatibilizer has a greater effect. 


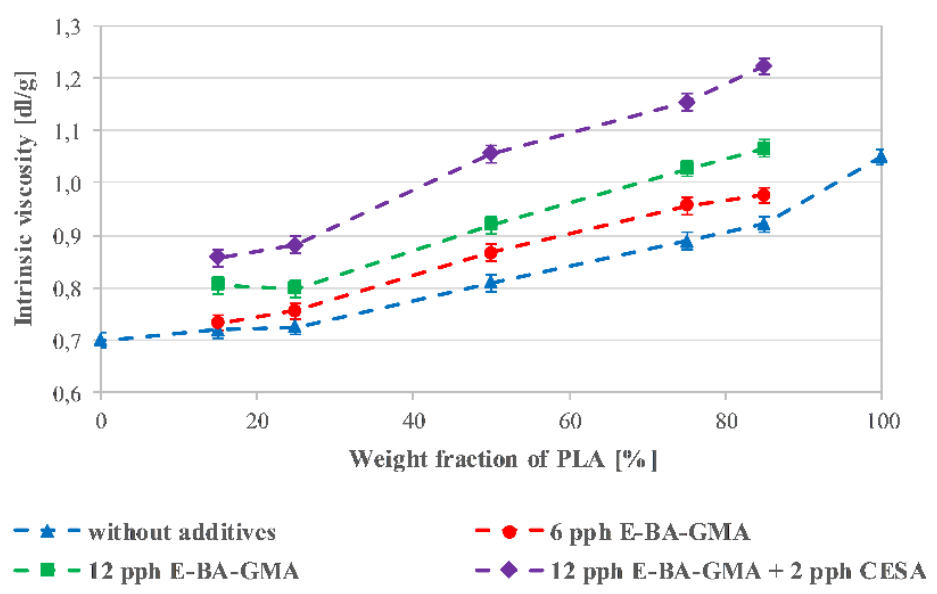

Figure 1 Intrinsic viscosities of different PET/PLA blends with and without additives

4 With the addition of compatibilizer and/or chain extender, the growth of IV may have been caused by a number of mechanisms, because the epoxide group in the backbone of additives can also react efficiently with the carboxyl $(-\mathrm{COOH})$ and hydroxyl $(-\mathrm{OH})$ end groups of PET and PLA. As a result, they were able to combine two PET chains, two PLA chains and also a PET and PLA chain, and crosslinking may have occurred too.

\subsection{Mechanical properties}

11 The results of the tensile test showed that in the case of blends without additives, the 85/15

12 PET/PLA blend was broken after neck formation, while in all other cases, the test specimens were broken rigidly. However, with the addition of the compatibilizer, the blends became 14 tougher.

15 Figure 2 shows the tensile stress-strain curves of the 15/85 PET/PLA blends with and without additives. The curves show that the blends without additives were brittle, but with the addition

17 of the compatibilizer, the blends became tougher and elongation at break increased 18 significantly. When we used compatibilizer and chain extender simultaneously, elongation at break more than doubled compared to the blend which contains only 12 pph E-BA-GMA. The characteristics of the curves also showed a similar tendency for the other blends. 


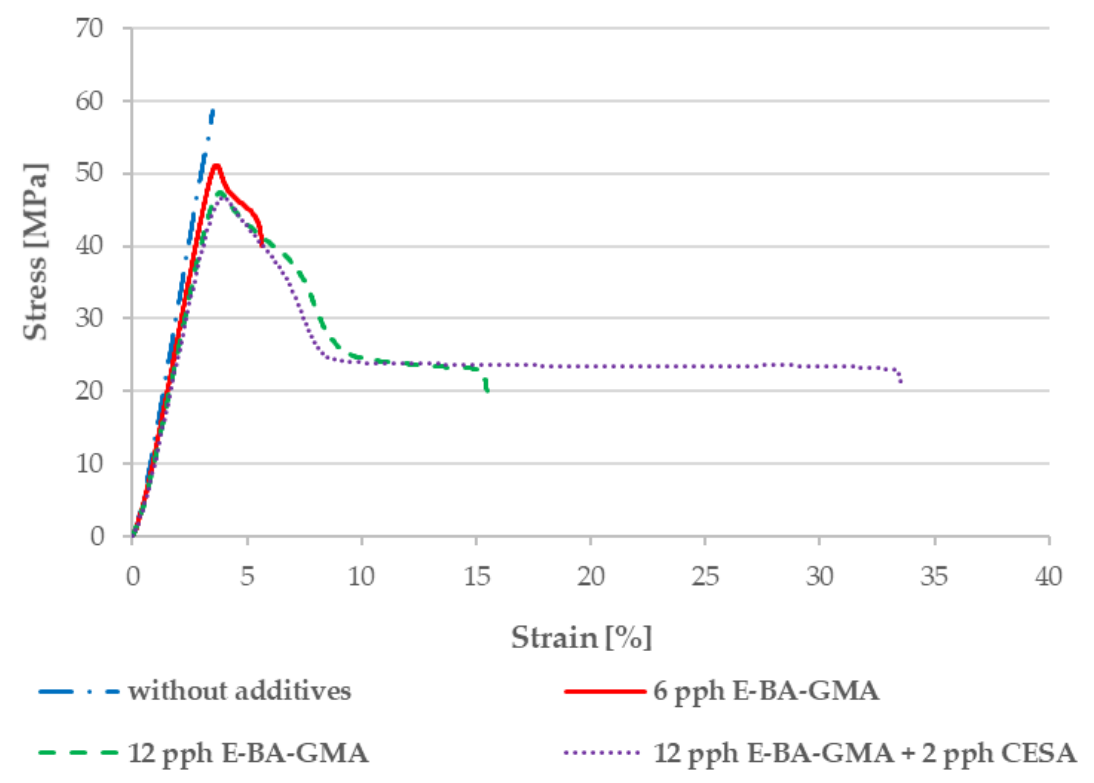

Figure 2 Stress-strain curves of 15/85 PET/PLA blends with and without additives 3

4 Figure 3 shows the tensile strength of the different PET/PLA blends, which was calculated at the $1^{\text {st }}$ local maximum of the tensile curve. With all blends, tensile strength decreases as the ratio of E-BA-GMA increases. This can be explained by the fact that E-BA-GMA structurally softens the blends.

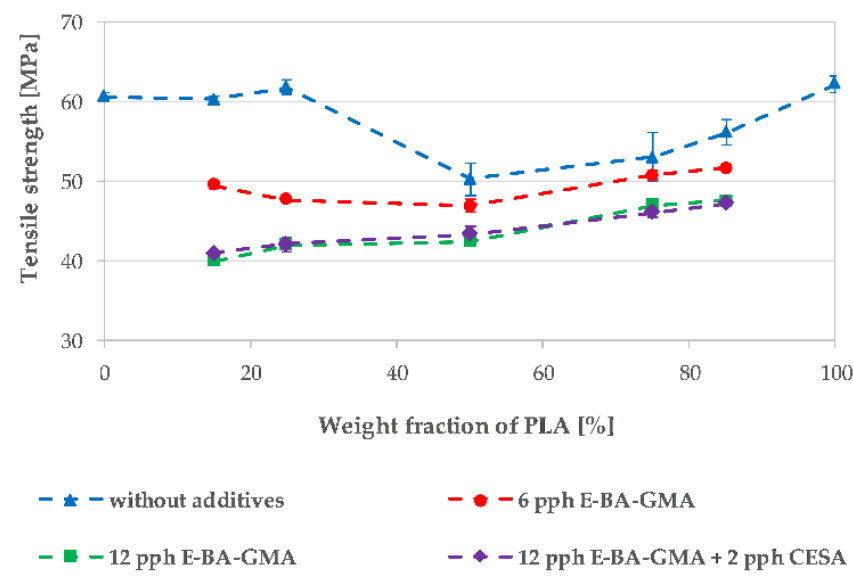

Figure 3 Tensile strength of PET/PLA blends of different weight ratios with and without additives

13 Figure 4 shows the elongation at maximum force, depending on the ratio of PLA to various 14 additive contents. Elongation at maximum force was nearly the same for blends which contain $1515 \%$ and $25 \%$ PLA with or without additives. In contrast, above $25 \%$ of PLA content, without compatibilizer, the elongation at maximum force of the blends is reduced to two-thirds, due to 
1 the fact that, besides the higher PLA content, the blends were broken in a brittle way. However, 2 with the addition of compatibilizer, as the weight fraction of PLA increases, the elongation at 3 maximum force gradually decreased, but brittle fracture was replaced by tough fracture due to 4 the tough behaviour of the additive.

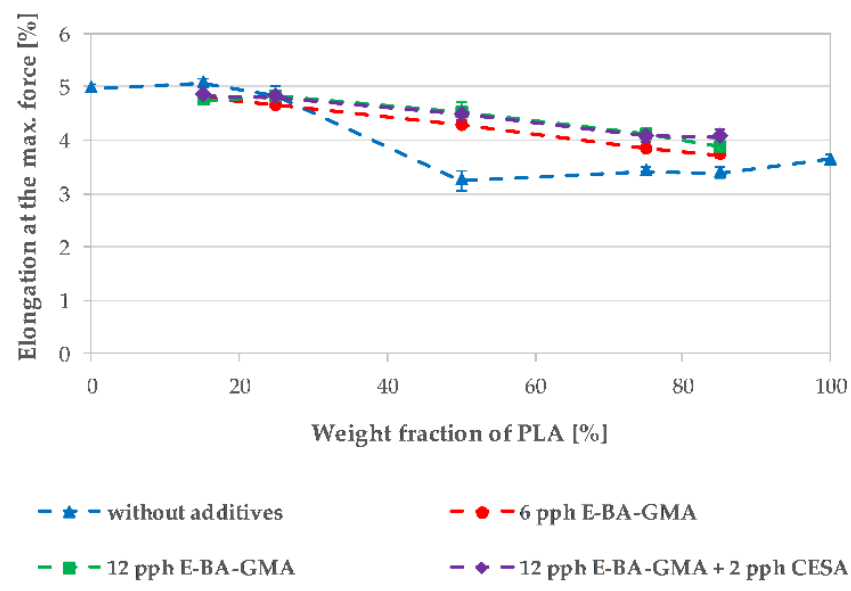

6

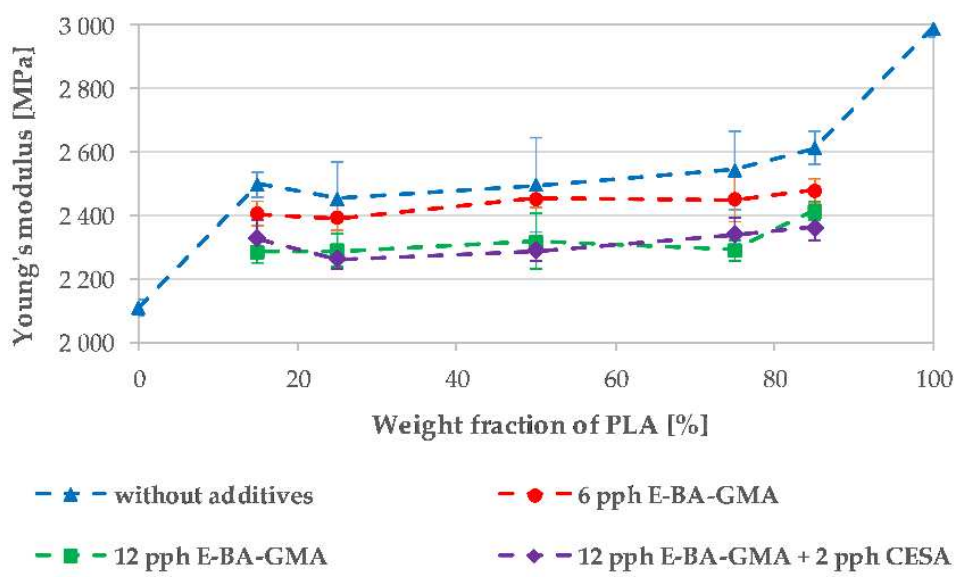

Figure 5 Young's modulus of PET/PLA blends of different weight ratios with and without additives 
1 The specific work of fracture (the area under the stress-strain curve divided by the cross-section

2 of the specimen) of the uncompatibilized and compatibilized PET/PLA blends was shown in

3 Figure 6. The two materials behaved as expected; neat PET was ductile, while neat PLA

4 behaved brittle. Without additives, the specific work of fracture does not change with the increase of PLA. Neat PET, however, has a far higher specific work of fracture. With the addition of the compatibilizer, the blends became tougher and elongation at break increased significantly, resulting in a higher specific work of fracture. Due to the rigid behaviour of the PLA, the specific work of fracture of compatibilized blends decreased with the increase of PLA, above $25 \%$ of PLA content. However, the specific work of fracture, even for the $15 / 85$ PET/PLA blend, increased tenfold with the addition of 10 pph E-BA-GMA and 2 pph CESA simultaneously, compared to the uncompatibilized blend.

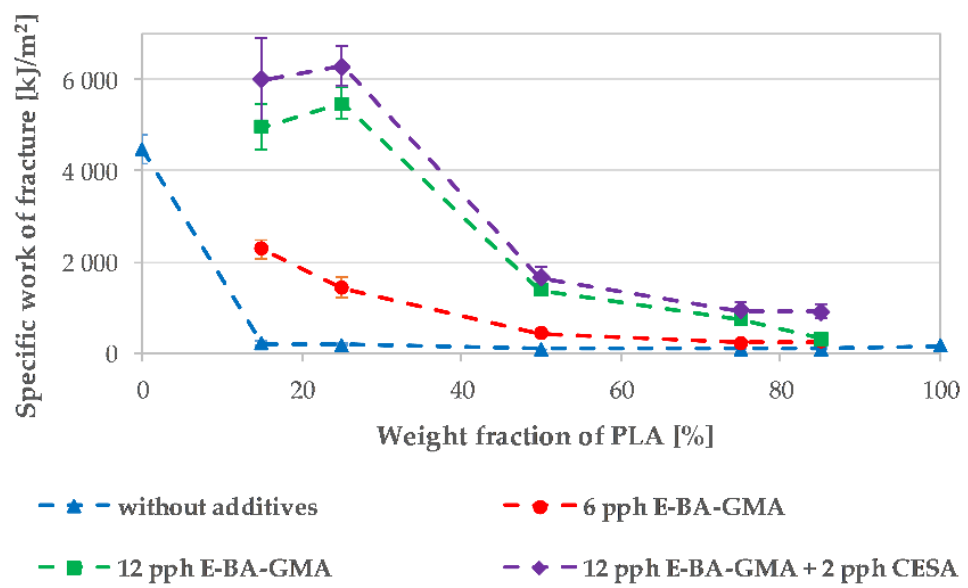

Figure 6 The specific work of fracture of different uncompatibilized and compatibilized

Figure 7 shows Charpy impact strength as a function of the ratio of PLA to various additive contents. Without compatibilizer, impact strength does not change with the increase of PLA. As the amount of compatibilizer increases, the impact strength is gradually increased and, as with the tensile test, the impact strength is further increased when a chain extender is used at the same time. This growth may be caused by a number of mechanisms; on the one hand, the soft/tough segments in the E-BA-GMA, and on the other hand, longer polymer chains could form in the blends due to the effect of the compatibilizer and the chain extender. In addition, cross-linking of the polymer chains could occur with additives. Also, decreased droplet size and finer particle size distribution of the dispersed phase (see Table 2) may also have led to the increase of impact strength. The results of the Charpy impact strength, which expresses 
1 dynamic fracture toughness, show similar trends as the specific work of fracture, which 2 expresses static fracture toughness.

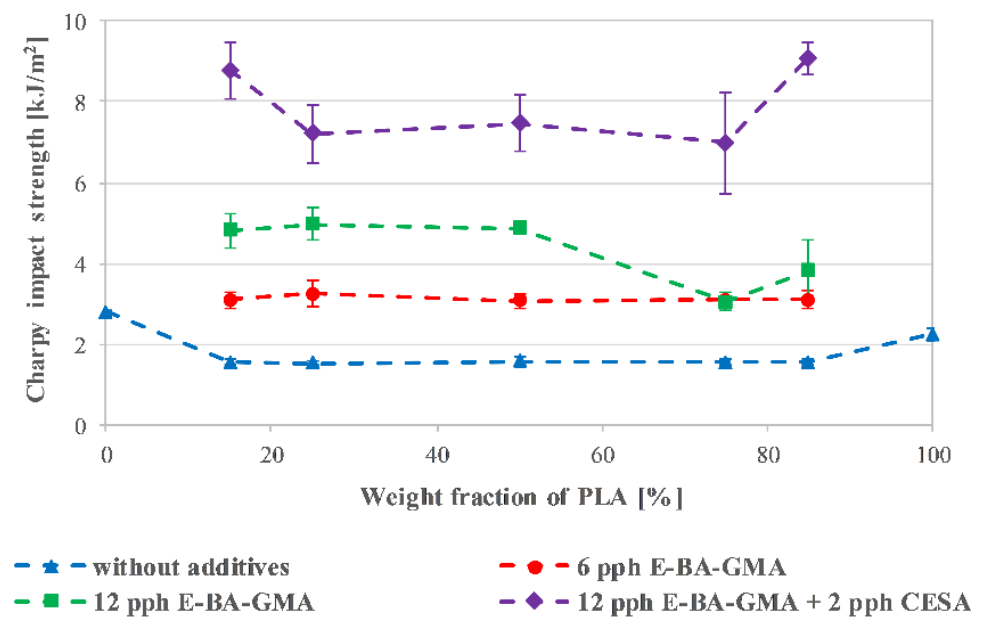

Figure 7 Charpy impact strength of different PET/PLA blends with and without compatibilizers

\subsection{Miscibility and phase morphology}

We also studied the structure of the different uncompatibilized and compatibilized blends by SEM (Table 2). The SEM micrographs indicated that a dispersed phase structure (island-sea type morphology) was formed in all blends (Figure 8). While in the blends containing 15\% and $25 \%$ PLA, the PET was the matrix, in the blends containing 50\%, 75\% and 85\% PLA, the PLA was the matrix and the PET was the dispersed phase. The SEM micrographs show that the addition of compatibilizers resulted in a decreased diameter of the dispersed particles and a finer particle size distribution. However, in addition to the dispersed PLA phase, a second dispersed phase appeared in the compatibilized 85/15 and 75/25 PET/PLA blends, which is most likely formed by E-BA-GMA. 


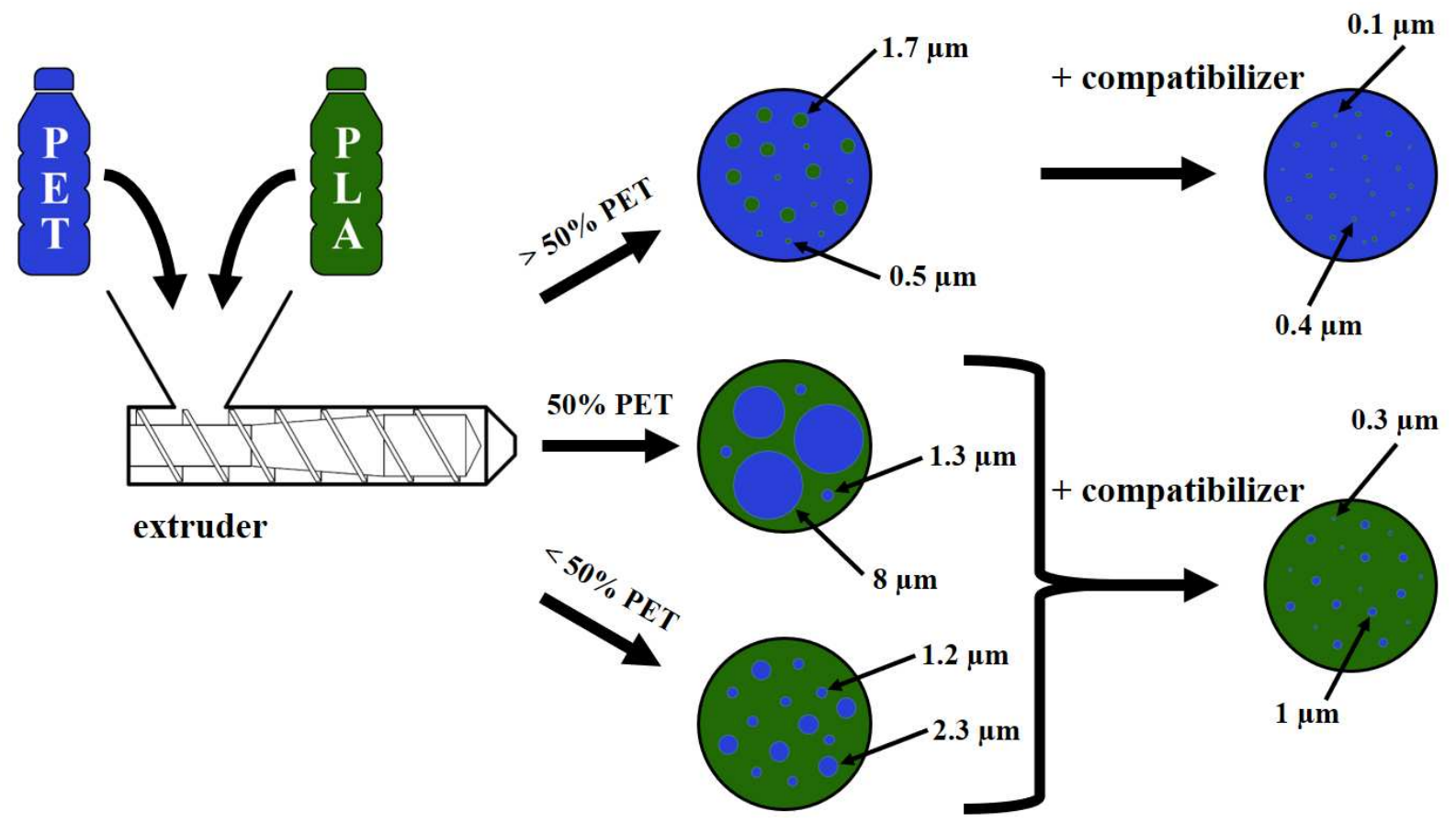

$2 \quad$ Figure 8 Dispersed phase structures of different uncompatibilized and compatibilized 3 PET/PLA blends

4 
1

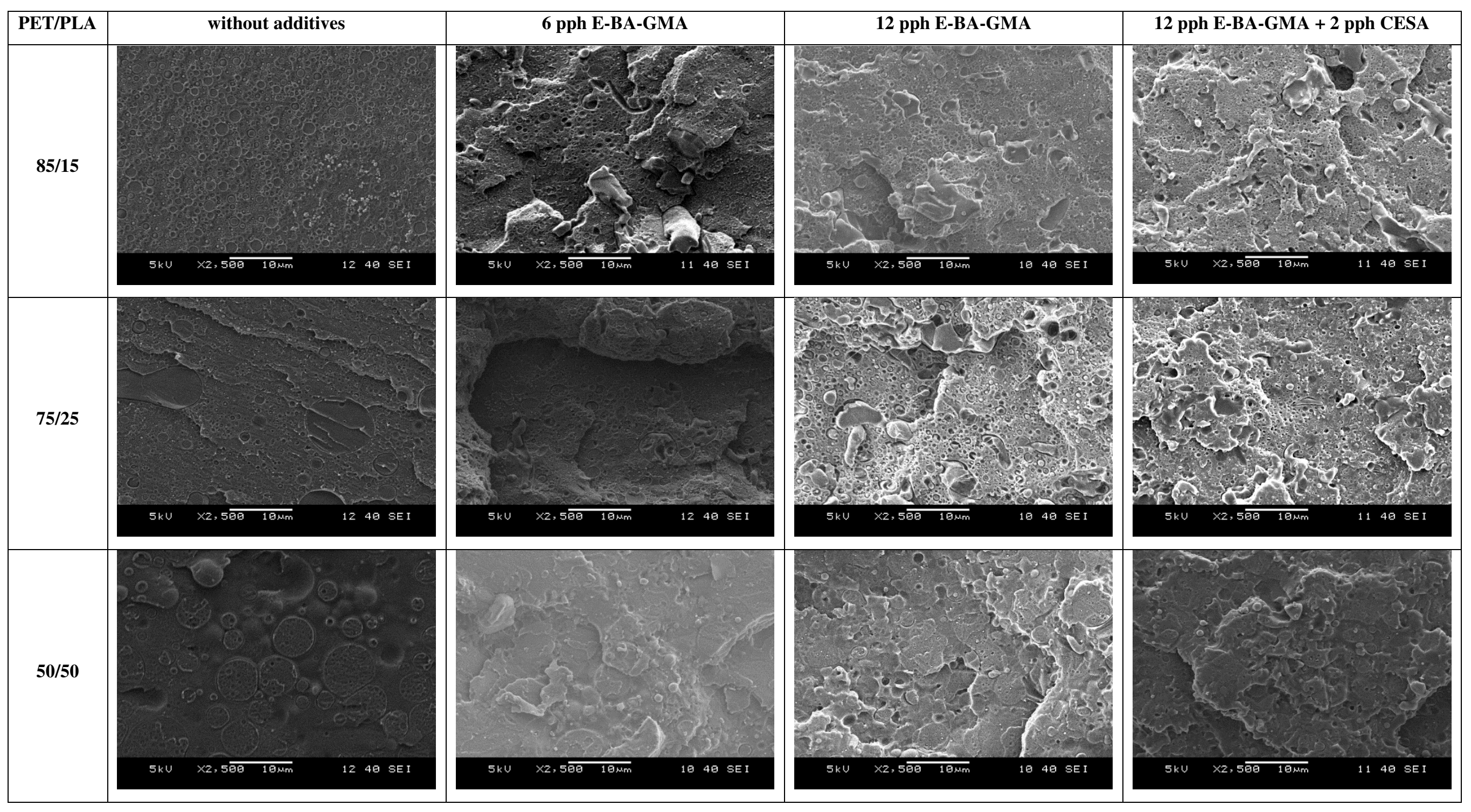




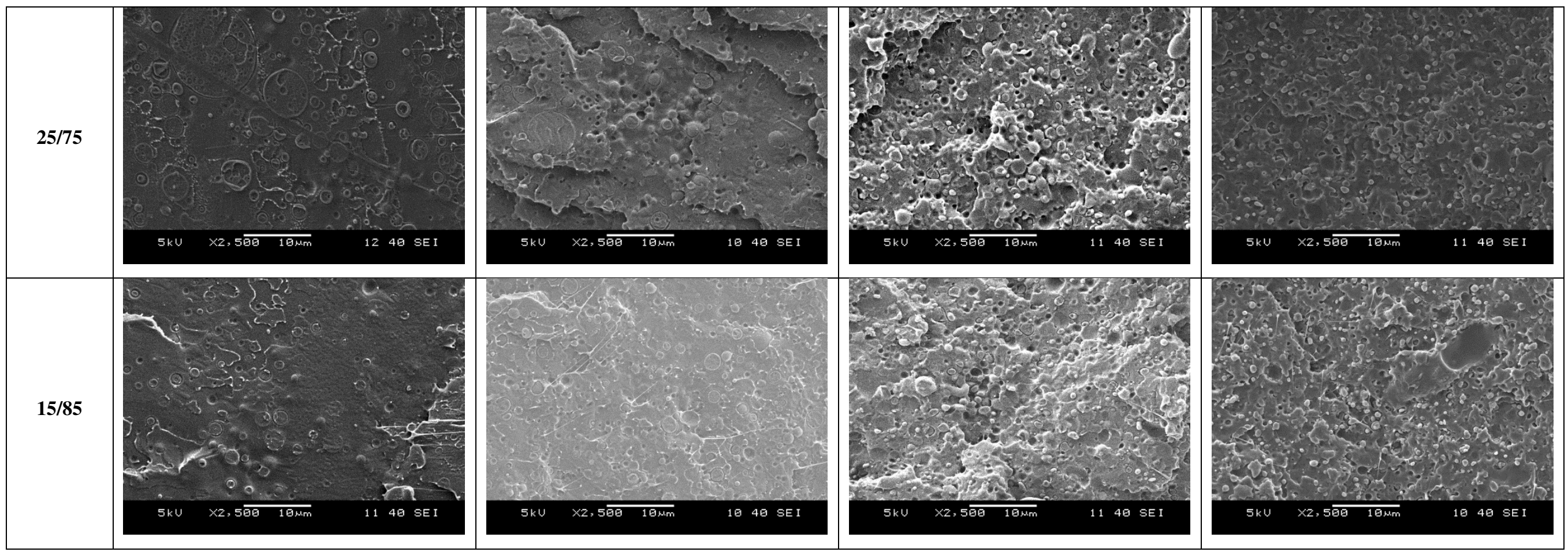

1

Table 2 SEM micrographs of different uncompatibilized and compatibilized PET/PLA blends 


\section{$1 \quad$ 3.4. Thermal stability}

2 Figure 9 shows the mass losses in the TGA test in an industrial air atmosphere at $50{ }^{\circ} \mathrm{C}$ to $3600{ }^{\circ} \mathrm{C}$ for uncompatibilized and compatibilized 75/25 PET/PLA blends. The shape of the 4 curves also showed a similar tendency for the other blends.

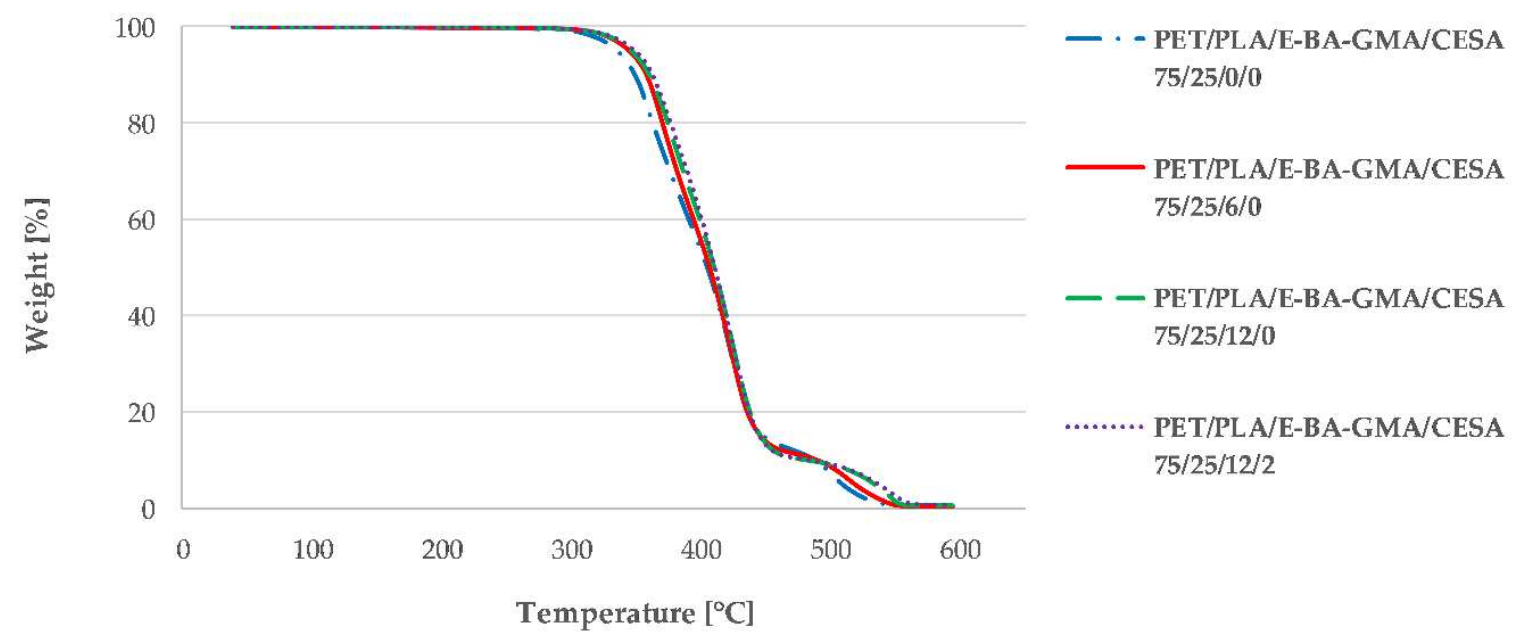

Figure 9 Mass losses of the uncompatibilized and compatibilized 75/25 PET/PLA blends in an industrial air atmosphere

The derivative thermogravimetry (DTG) curves of the uncompatibilized and compatibilized

11 75/25 PET/PLA blends is shown in Figure 10, where the most intense decomposition temperature ranges can be seen. There are three distinct peaks on the DTG curves, where the 13 first, between $300{ }^{\circ} \mathrm{C}$ and $400{ }^{\circ} \mathrm{C}$, is related to PLA and the other two, between $400{ }^{\circ} \mathrm{C}$ and 500 $14{ }^{\circ} \mathrm{C}$, and between $500{ }^{\circ} \mathrm{C}$ and $600{ }^{\circ} \mathrm{C}$, are related to PET. According to the literature [51], in the 15 case of PET, the first peak $\left(400{ }^{\circ} \mathrm{C}-500^{\circ} \mathrm{C}\right)$ is due to degradation of PET chains, while the second peak $\left(500{ }^{\circ} \mathrm{C}-600{ }^{\circ} \mathrm{C}\right)$ is due to thermo-oxidative degradation of PET. The shape of the curves also showed a similar tendency for the other blends. 


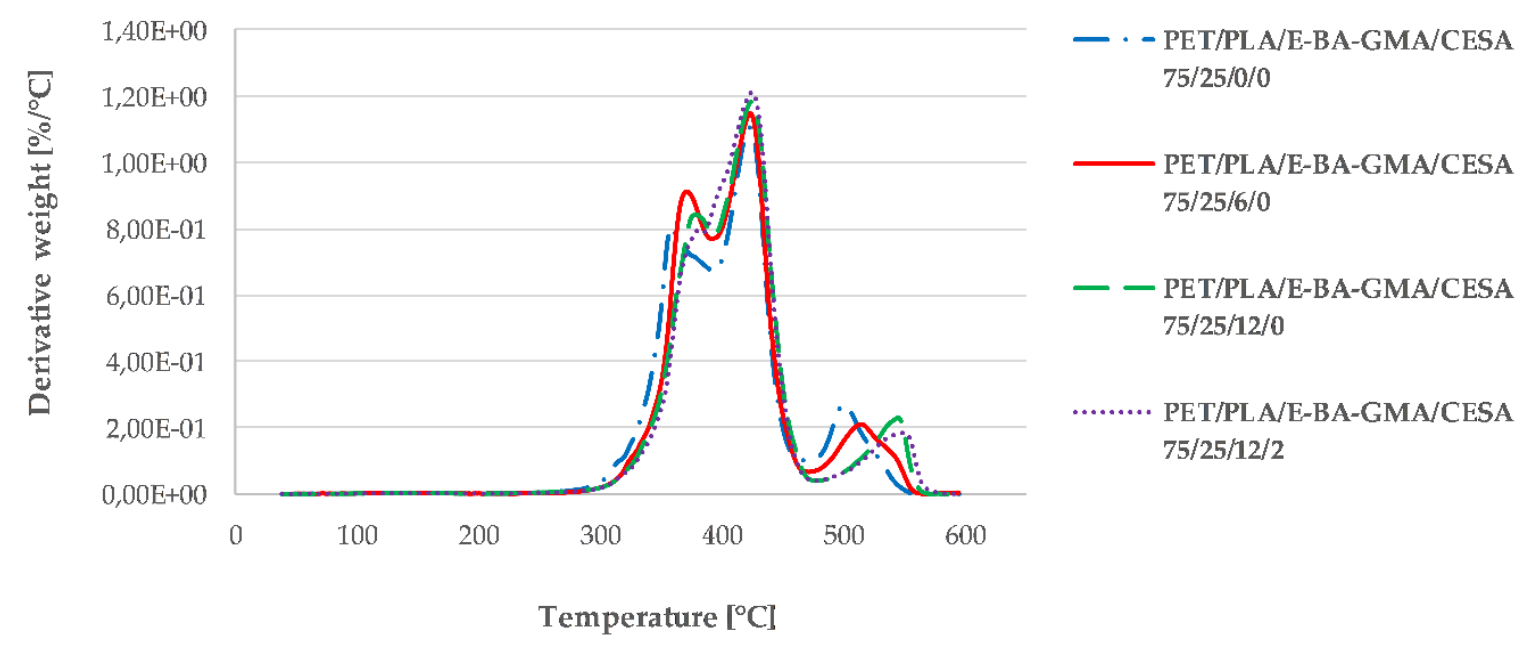

Figure 10 DTG curves of 75/25 PET/PLA blends with and without additives

4 Table 3 shows the results of the TGA measurements: the degradation onset temperature $\left(\mathrm{T}_{5}\right)$, 5 (the temperature at which $5 \mathrm{wt} \%$ degradation occurred) and the maximum degradation 6 temperatures (the peak temperature of the DTG curve) related to PLA (T $T_{\max }$ (PLA)) and PET 7 ( $\mathrm{T}_{\max (\mathrm{PET}}$ I.), $\mathrm{T}_{\max }$ (PET II.)). In the case of uncompatibilized blends, the degradation onset temperature and the maximum degradation temperatures related to PET and PLA were shifted to lower temperatures as the weight fraction of PLA increased. This can be explained by the fact that the thermal stability of PLA is lower than that of PET. In the case of blends containing $15 \%, 50 \%$, and $75 \%$ PLA, the degradation onset temperature of the blends was not altered by the addition of additives in different proportions. However, in the case of blends containing $25 \%$ and $85 \%$ PLA, T5 increased by $10{ }^{\circ} \mathrm{C}$ and $20{ }^{\circ} \mathrm{C}$ when E-BA-GMA was added, and a

14 further increase, $4{ }^{\circ} \mathrm{C}$ and $11{ }^{\circ} \mathrm{C}$, respectively, was observed when a chain extender was used with E-BA-GMA. With the exception of the 50/50 PET/PLA blend, the maximum degradation temperature associated with PLA shifted to higher temperatures due to the compatibilizer and the chain extender. Up to $50 \%$ of PLA, the additives had no effect on $\mathrm{T}_{\max }$ (PET I.), although this peak was not detected on the DTG curves for the compatibilized 25/75 and 15/85 PET/PLA blends. The $\mathrm{T}_{\max }$ (PET II.) peaks associated with the thermo-oxidative degradation of PET were also shifted to higher temperatures when compatibilizer and chain extender were both added.

\begin{tabular}{|c|c|c|c|c|c|}
\hline \multicolumn{2}{|c|}{ PET/PLA/E-BA-GMA/CESA } & $\mathbf{T}_{\mathbf{5}}\left[{ }^{\circ} \mathbf{C}\right]$ & $\mathbf{T}_{\max (\mathbf{P L A})}\left[{ }^{\circ} \mathbf{C}\right]$ & $\mathbf{T}_{\max (\mathbf{P E T} \text { I.) }}\left[{ }^{\circ} \mathbf{C}\right]$ & $\mathbf{T}_{\max (\mathbf{P E T} \text { II.) }}\left[{ }^{\circ} \mathbf{C}\right]$ \\
\hline $\mathbf{1 .}$ & $\mathbf{1 0 0 / 0 / 0 / 0}$ & 371.0 & - & 425.6 & 536.0 \\
\hline $\mathbf{2 .}$ & $\mathbf{8 5 / 1 5 / 0 / 0}$ & 354.0 & 371.9 & 424.4 & 536.8 \\
\hline $\mathbf{3 .}$ & $\mathbf{8 5 / 1 5 / 6 / 0}$ & 350.5 & 381.4 & 424.8 & 540.8 \\
\hline $\mathbf{4 .}$ & $\mathbf{8 5 / 1 5 / 1 2 / 0}$ & 354.5 & 384.6 & 429.2 & 545.7 \\
\hline
\end{tabular}




\begin{tabular}{|c|c|c|c|c|c|}
\hline 5. & $85 / 15 / 12 / 2$ & 352.6 & 386.5 & 424.6 & 552.4 \\
\hline 6. & $75 / 25 / 0 / 0$ & 335.5 & 359.0 & 423.0 & 500.9 \\
\hline 7. & $75 / 25 / 6 / 0$ & 344.9 & 370.8 & 423.6 & 514.9 \\
\hline 8. & $75 / 25 / 12 / 0$ & 346.8 & 379.0 & 425.0 & 545.1 \\
\hline 9. & $75 / 25 / 12 / 2$ & 349.3 & 381.8 & 424.9 & 550.3 \\
\hline 10. & $50 / 50 / 0 / 0$ & 331.3 & 364.2 & 419.0 & 529.0 \\
\hline 11. & $50 / 50 / 6 / 0$ & 331.7 & 361.5 & 417.6 & 525.1 \\
\hline 12. & $50 / 50 / 12 / 0$ & 338.1 & 368.7 & 417.6 & 537.2 \\
\hline 13. & $50 / 50 / 12 / 2$ & 324.7 & 365.8 & 420.4 & 543.4 \\
\hline 14. & $25 / 75 / 0 / 0$ & 318.7 & 353.3 & 412.4 & 513.5 \\
\hline 15. & $25 / 75 / 6 / 0$ & 325.5 & 359.6 & - & 512.9 \\
\hline 16. & $25 / 75 / 12 / 0$ & 329.3 & 361.0 & - & 525.6 \\
\hline 17. & $25 / 75 / 12 / 2$ & 329.8 & 360.6 & - & 543.3 \\
\hline 18. & $15 / 85 / 0 / 0$ & 286.3 & 323.4 & 406.6 & 466.6 \\
\hline 19. & $15 / 85 / 6 / 0$ & 295.9 & 331.1 & - & 466.0 \\
\hline 20. & $15 / 85 / 12 / 0$ & 306.6 & 338.8 & - & 478.8 \\
\hline 21. & $15 / 85 / 12 / 2$ & 317.9 & 341.9 & - & 467.3 \\
\hline 22. & $0 / \mathbf{1 0 0 / 0 / 0}$ & 312.3 & 335.9 & - & - \\
\hline
\end{tabular}

1 Table 3. Onset degradation temperature at $5 \%$ weight loss $\left(\mathrm{T}_{5}\right)$ and temperatures at maximum degradation rate for PLA ( $\left.\mathrm{T}_{\operatorname{maxPLA}}\right)$ and PET ( $\left.\mathrm{T}_{\max (\text { PET I.) }}, \mathrm{T}_{\max (\mathrm{PET} \text { II.) }}\right)$

4 The increase in thermal stability may have been caused by different mechanisms. On the one 5 hand, due to the effect of the compatibilizer and chain extender, longer polymer chains may have been formed in the blend, thereby reducing the number of carboxyl end groups. A number of publications [52-55] have also concluded that thermal stability increases as the number of carboxyl end groups decrease. On the other hand, cross-linking between the polymer chains also occurred when additives were added, and these require more energy to break up. In addition, the benzene ring in the chain extender may also have increased the thermal stability 11 of the blends.

\section{Conclusions}

14 Nowadays, besides economic interests and social expectations, European Union directives also control and limit the amount of packaging materials that can be used and their recycling rates.

16 In 2017, only $2 \%$ of the total production of plastics was biopolymer, but in the coming years, 17 its volume is expected to increase drastically. 
1 In our research, we improved the recyclability of mixed PET/PLA bottles. In our experiments,

2 we investigated the intrinsic viscosities, mechanical properties, SEM micrographs and thermal 3 stability of the uncompatibilized and compatibilized PET/PLA blends of different weight ratios.

4 We applied E-BA-GMA terpolymer as a compatibilizer and used a masterbatch which contains the chain extender Joncryl ADR 4368 to increase molecular weight and utilize its reactive functional groups to improve miscibility. We made 22 different compounds with a twin-screw extruder. During the injection molding of the blends, we found that the compatibilizer made it easier to remove the specimens from the mold. From the change in IVs, we concluded that different reactions could occur between the polymer chains due to the compatibilizers, resulting in an increase in the molecular weight of the blends. As the epoxide group in the backbone of additives can also react efficiently with the carboxyl and hydroxyl end groups of PET and PLA, PET chains, PLA chains, and PET and PLA chains may have been linked, and also crosslinking may have occurred. We found that the blends become tougher; elongation at break and Charpy impact strength increased around tenfold and fivefold, respectively, when E-BA-GMA was added, because of the high level of butyl acrylate. A further improvement was observed when we used E-BA-GMA and the chain extender simultaneously. However, due to the composition of E-BA-GMA, the Young's modulus of the blends decreased. The SEM micrographs indicated that a dispersed phase structure (island-sea type morphology) formed in all blends. The additives reduced the diameter of the dispersed particles and particle size distribution was finer, therefore it can be stated that E-BA-GMA was an effective compatibilizer in the blends. The applied compatibilizers increased the thermal stability of the blends and shifted the maximum degradation temperatures towards higher temperatures. This can be explained by the fact that the compatibilizers reduced the number of carboxyl end groups in the blends. Moreover, the additives may also have resulted in cross-linking between the polymer chains, which would require more energy to degrade. Additionally, the benzene ring in the chain extender may also have increased the thermal stability of the blends.

Compared to the uncompatibilized blends, the compatibilized blends may once again be suitable for use in the packaging industry or the food industry, because, according to DuPont [31], crystallized PET trays containing no more than 7\% E-BA-GMA fully comply with the Federal Food, Drug, and Cosmetic Act, and all applicable food additive regulations. Also, the compatibilized blends may also be suitable for engineering applications due to their tough behaviour.

At the same time, a condition of the application of the blends and additives is cost effectiveness. 
1 ordered volume), we have carried out an approximate cost analysis. The sorted, separated and 2 washed PET bottle flakes cost around $1 € / \mathrm{kg}$, but the price of the mixed PET/PLA bottle flakes 3 will probably be much lower (around $0.4-0.8 € / \mathrm{kg}$ ), depending on purity and homogeneity. E4 BA-GMA costs around $5 € / \mathrm{kg}$ and CESA costs around $10 € / \mathrm{kg}$. Based on these prices, $12 \mathrm{pph}$ E-BA-GMA and 2 pph CESA increase the cost of the blends by $0.8 € / \mathrm{kg}$. It is true that the price of the blends is a little bit higher than virgin PET (around $1.1 € / \mathrm{kg}$ ), but at the same time, the improvement in mechanical properties makes it one of the technical plastics $(2-3 € / \mathrm{kg})$ where the price is competitive.

\section{Acknowledgements}

This work was supported by the National Research, Development and Innovation Office (grant number: NVKP_16-1-2016-0012) and by the Higher Education Excellence Program of the Ministry of Human Capacities in the framework of the Nanotechnology research area of the Budapest University of Technology and Economics (BME FIKP-NANO). The infrastructure of the research project was supported by Jász-Plasztik Ltd.

\section{References}

18 [1] PlasticsEurope: Plastics - the Facts 2018. PlasticsEurope AISBL, Brussels (2018).

19 [2] European Bioplastics: Bioplastics market data 2018. European Bioplastics e.V., Berlin (2018).

20 [3] Geyer R., Jambeck J. R., Law K. L.: Production, use, and fate of all plastics ever made. Science Advances,

[4] European Commission - Press release: Circular Economy: Commission welcomes Council final adoption of new rules on single-use plastics to reduce marine plastic litter. Brussels, 21 May 2019. http://europa.eu/rapid/press-release_IP-19-2631_en.htm

[5] Formela K., Zedler Ł., Hejna A., Tercjak A.: Reactive extrusion of bio-based polymer blends and composites - Current trends and future developments. Express Polymer Letters, 12, 24-57 (2018).

[6] Nova-Institut: Bio-based Building Blocks and Polymers - Global Capacities, Production and Trends 2018 - 2023. Nova-Institut GmbH, Hürth (2019).

[7] Chow W. S., Teoh E. L., Karger-Kocsis J.: Flame retarded poly(lactic acid): A review. Express Polymer Letters, 12, 396-417 (2018).

[8] Kmetty Á., Litauszki K., Réti D.: Characterization of different chemical blowing agents and their applicability to produce poly(lactic acid) foams by extrusion. Applied Sciences, 8, 1960 (2018).

[9] Chen H., Yu X., Zhou W., Peng S., Zhao X.: Highly toughened polylactide (PLA) by reactive blending with novel polycaprolactone-based polyurethane (PCLU) blends. Polymer Testing, 70, 275-280 (2018).

[10] Litauszki K., Kovács Z., Mészáros L., Kmetty Á.: Accelerated photodegradation of poly(lactic acid) with weathering test chamber and laser exposure - A comparative study. Polymer Testing, 76, 411-419 (2019).

[11] Mazidi M. M., Berahman R., Edalat A.: Phase morphology, fracture toughness and failure mechanisms in super-toughened PLA/PB-g-SAN/PMMA ternary blends: A quantitative analysis of crack resistance. Polymer Testing, 67, 380-391 (2018).

[12] Soroudi A., Jakubowicz I.: Recycling of bioplastics, their blends and biocomposites: A review. European Polymer Journal, 49, 2839-2858 (2013).

[13] La Mantia F. P., Botta L., Morreale M., Scaffaro R.: Effect of small amounts of poly(lactic acid) on the recycling of poly(ethylene terephthalate) bottles. Polymer Degradation and Stability, 97, 21-24 (2012).

[14] Gere D., Czigány T.: Rheological and mechanical properties of recycled polyethylene films contaminated by biopolymer. Waste Management, 76, 190-198 (2018). 
[15] Torres-Huerta A. M., Palma-Ramírez D., Domínguez-Crespo M. A., Del Angel-López D., de la Fuente D.: Comparative assessment of miscibility and degradability on PET/PLA and PET/chitosan blends. European Polymer Journal, 61, 285-299 (2014).

[16] Gere D., Czigány T.:Recycling of mixed poly(ethylene-terephthalate) and poly(lactic acid). in 'MATEC Web of Conferences. Paris, Vol 253, 02005 (2019).

[17] Alaerts L., Augustinus M., Van Acker K.: Impact of bio-based plastics on current recycling of plastics. Sustainability, 10, (2018).

[18] Gent M. R., Menendez M., Toraño J., Diego I.: Recycling of plastic waste by density separation: prospects for optimization. Waste Management \& Research, 27, 175-187 (2009).

[19] Cornell D. D.: Biopolymers in the existing postconsumer plastics recycling stream. Journal of Polymers and the Environment, 15, 295-299 (2007).

[20] Zsíros L., Kovács J. G.: Surface homogeneity of injection molded parts. Periodica Polytechnica Mechanical Engineering, 62, 284-291 (2018).

[21] Maris J., Bourdon S., Brossard J.-M., Cauret L., Fontaine L., Montembault V.: Mechanical recycling: Compatibilization of mixed thermoplastic wastes. Polymer Degradation and Stability, 147, 245-266 (2018).

[22] Muthuraj R., Misra M., Mohanty A. K.: Biodegradable compatibilized polymer blends for packaging applications: A literature review. Journal of Applied Polymer Science, 135, 45726 (2018).

[23] Koning C., Van Duin M., Pagnoulle C., Jerome R.: Strategies for compatibilization of polymer blends. Progress in Polymer Science, 23, 707-757 (1998).

[24] Zeng J.-B., Li K.-A., Du A.-K.: Compatibilization strategies in poly(lactic acid)-based blends. RSC Advances, 5, 32546-32565 (2015).

[25] Wu D., Zhang Y., Yuan L., Zhang M., Zhou W.: Viscoelastic interfacial properties of compatibilized poly(E-caprolactone)/polylactide blend. Journal of Polymer Science: Part B: Polymer Physics, 48, 756765 (2010).

[26] Kim C.-H., Cho K. Y., Choi E.-J., Park J.-K.: Effect of P(ILA-co- $\varepsilon C L)$ on the compatibility and crystallization behavior of PCL/PLLA blends. Journal of Applied Polymer Science, 77, 226-231 (2000).

[27] Supthanyakul R., Kaabbuathong N., Chirachanchai S.: Random poly(butylene succinate-co-lactic acid) as a multi-functional additive for miscibility, toughness, and clarity of PLA/PBS blends. Polymer, 105, 1-9 (2016).

[28] Na Y.-H., He Y., Shuai X., Kikkawa Y., Doi Y., Inoue Y.: Compatibilization effect of poly(Ecaprolactone)-b-poly(ethylene glycol) block copolymers and phase morphology analysis in immiscible poly(lactide)/poly( $\varepsilon$-caprolactone) blends. Biomacromolecules, 3, 1179-1186 (2002).

[29] Yang X., Finne-Wistrand A., Hakkarainen M.: Improved dispersion of grafted starch granules leads to lower water resistance for starch-g-PLA/PLA composites. Composites Science and Technology, 86, 149156 (2013).

[30] Chen L., Qiu X., Xie Z., Hong Z., Sun J., Chen X., Jing X.: Poly(L-lactide)/starch blends compatibilized with poly(L-lactide)-g-starch copolymer. Carbohydrate Polymers, 65, 75-80 (2006).

[31] DuPont: Elvaloy ${ }^{\circledR}$ resins Product Data Sheet. DuPont, Wilmington (2016).

[32] Lu X., Tang L., Wang L., Zhao J., Li D., Wu Z., Xiao P.: Morphology and properties of bio-based poly (lactic acid)/high-density polyethylene blends and their glass fiber reinforced composites. Polymer Testing, 54, 90-97 (2016).

[33] Kumar M., Mohanty S., Nayak S. K., Rahail Parvaiz M.: Effect of glycidyl methacrylate (GMA) on the thermal, mechanical and morphological property of biodegradable PLA/PBAT blend and its nanocomposites. Bioresource Technology, 101, 8406-8415 (2010).

[34] Yang L., Chen H., Jia S., Lu X., Huang J., Yu X., Ye K., He G., Qu J.: Influences of ethylenebutylacrylate-glycidyl methacrylate on morphology and mechanical properties of poly(butylene terephthalate)/polyolefin elastomer blends. Journal of Applied Polymer Science, 131, 40660 (2014).

[35] Zhang C., Dai G.: Mechanical properties and reactions of PBT/PTW blends. Journal of Materials Science, 42, 9947-9953 (2007).

[36] Kaci M., Benhamida A., Cimmino S., Silvestre C., Carfagna C.: Waste and virgin LDPE/PET blends compatibilized with an ethylene-butyl acrylate-glycidyl methacrylate (EBAGMA) Terpolymer, 1. Macromolecular Materials and Engineering, 290, 987-995 (2005).

[37] Benhamida A., Kaci M., Cimmino S., Silvestre C., Duraccio D.: Evaluation of the effectiveness of new compatibilizers based on EBAGMA-LDPE and EBAGMA-PET masterbatches for LDPE/PET blends. Macromolecular Materials and Engineering, 295, 222-232 (2010).

[38] Kang H., Lu X., Xu Y.: Properties of immiscible and ethylene-butyl acrylate-glycidyl methacrylate terpolymer compatibilized poly (lactic acid) and polypropylene blends. Polymer Testing, 43, 173-181 (2015). 
[39] Khonakdar H. A., Jafari S. H., Mirzadeh S., Kalaee M. R., Zare D., Saeb M. R.: Rheology-morphology correlation in PET/PP blends: Influence of type of compatibilizer. Journal of Vinyl \& Additive Technology, 19, 25-30 (2013).

[40] Li S.-C., Lu L.-N.: Melt rheological properties of reactive compatibilized HDPE/PET blends. Journal of Applied Polymer Science, 108, 3559-3564 (2008).

[41] Xiao L., Wang H., Qian Q., Jiang X., Liu X., Huang B., Chen Q.: Molecular and structural analysis of epoxide-modified recycled poly(ethylene terephthalate) from rheological data. Polymer Engineering \& Science, 52, 2127-2133 (2012).

[42] Duarte I. S., Tavares A. A., Lima P. S., Andrade D. L. A. C. S., Carvalho L. H., Canedo E. L., Silva S. M. L.: Chain extension of virgin and recycled poly(ethylene terephthalate): Effect of processing conditions and reprocessing. Polymer Degradation and Stability, 124, 26-34 (2016).

[43] Al-Itry R., Lamnawar K., Maazouz A.: Improvement of thermal stability, rheological and mechanical properties of PLA, PBAT and their blends by reactive extrusion with functionalized epoxy. Polymer Degradation and Stability, 97, 1898-1914 (2012).

[44] Bocz K., Molnár B., Marosi G., Ronkay F.: Preparation of low-density microcellular foams from recycled PET modified by solid state polymerization and chain extension. Journal of Polymers and the Environment, 27, 343-351 (2019).

[45] Mallet B., Lamnawar K., Maazouz A.: Improvement of blown film extrusion of poly(lactic acid): Structure-processing-properties relationships. Polymer Engineering \& Science, 54, 840-857 (2014).

[46] Abdelwahab M. A., Taylor S., Misra M., Mohanty A. K.: Thermo-mechanical characterization of bioblends from polylactide and poly(butylene adipate-co-terephthalate) and lignin. Macromolecular Materials and Engineering, 300, 299-311 (2015).

[47] You X., Snowdon M. R., Misra M., Mohanty A. K.: Biobased Poly(ethylene terephthalate)/Poly(lactic acid) Blends Tailored with Epoxide Compatibilizers. ACS Omega, 3, 11759-11769 (2018).

[48] Al-Itry R., Lamnawar K., Maazouz A.: Rheological, morphological, and interfacial properties of compatibilized PLA/PBAT blends. Rheologica Acta, 53, 501-517 (2014).

[49] Palsikowski P. A., Kuchnier C. N., Pinheiro I. F., Morales A. R.: Biodegradation in soil of PLA/PBAT blends compatibilized with chain extender. Journal of Polymers and the Environment, 26, 330-341 (2018).

[50] Quiles-Carrillo L., Montanes N., Garcia-Garcia D., Carbonell-Verdu A., Balart R., Torres-Giner S.: Effect of different compatibilizers on injection-molded green composite pieces based on polylactide filled with almond shell flour. Composites Part B: Engineering, 147, 76-85 (2018).

[51] Pan Y., Wang W., Pan H., Zhan J., Hu Y.: Fabrication of montmorillonite and titanate nanotube based coatings via layer-by-layer self-assembly method to enhance the thermal stability, flame retardancy and ultraviolet protection of polyethylene terephthalate (PET) fabric. RSC Advances, 6, 53625-53634 (2016).

[52] Scheirs J., Long T. E.: Modern polyesters: Chemistry and technology of polyesters and copolyesters. John Wiley \& Sons Ltd, Chichester (2003).

[53] Bikiaris D. N., Karayannidis G. P.: Effect of carboxylic end groups on thermooxidative stability of PET and PBT. Polymer Degradation and Stability, 63, 213-218 (1999).

[54] Liu B., Xu Q.: Effects of bifunctional chain extender on the crystallinity and thermal stability of PET. Journal of Materials Science and Chemical Engineering, 1, 9-15 (2013).

[55] Awaja F., Pavel D.: Recycling of PET. European Polymer Journal, 41, 1453-1477 (2005). 